\title{
Effect of Anchorage Number on Behavior of Reinforced Concrete Beams Strengthened with Glass Fiber Plates
}

\author{
Mustafa Kaya $^{1), *}$, and Zeynel Çağdaş Kankal ${ }^{2)}$ \\ (Received January 15, 2015, Accepted September 27, 2015, Published online December 10, 2015)
}

\begin{abstract}
Reinforced concrete beams with insufficient shear reinforcement were strengthened using glass fiber reinforced polymer (GFRP) plates. In the study, the effect of the number of bolts on the load capacity, energy dissipation, and stiffness of reinforced concrete beams were investigated by using anchor bolt of different numbers. Three strengthened with GFRP specimens, one flexural reference specimen designed in accordance to Regulation on Buildings Constructed in Disaster Areas rules, and one shear reinforcement insufficient reference specimen was tested. Anchorage was made on the surfaces of the beams in strengthened specimens using 2, 3 and 4 bolts respectively. All beams were tested under monotonic loads. Results obtained from the tests of strengthened concrete beams were compared with the result of good flexural reference specimen. The beam in which 4 bolts were used in adhering GFRP plates on beam surfaces carried approximately equal loads with the beam named as a flexural reference. The amount of energy dissipated by strengthened DE 5 specimen was $96 \%$ of the amount of energy dissipated by DE1 reference specimen. Strengthened DE5 specimen initial stiffness equal to DE1 reference specimen initial stiffness, but strengthened DE5 specimen yield stiffness about $4 \%$ lower than DE1 reference specimen yield stiffness. Also, DE5 specimen exhibited ductile behavior and was fractured due to bending fracture. Upon the increase of the number of anchorages used in a strengthening collapsing manner of test specimens changed and load capacity and ductility thereof increased.
\end{abstract}

Keywords: glass fibers, laminates, plates, adhesion, shear strengthening.

\section{Introduction}

In reinforced concrete beams very important shear problems are encountered due to projecting, material and application errors. Reinforced concrete specimens have the ductile behavior under bending effect. However, if these specimens have insufficient shear reinforcement, they are fractured suddenly and in a brittle manner.

In reinforced concrete beams, it is compulsory to place transverse reinforcement along the length of the beam in order to prevent shear cracks of beams (Regulation on Buildings Constructed in Disaster Areas 2007). Stirrups placed longitudinally as perpendicular to the reinforcement are used as shear reinforcement. In any beam with sufficient shear reinforcement bending cracks remain at low levels and the specimen exhibits the ductile behavior.

Some studies used steel plates or fiber reinforced polymer (FRP) sheets to improve the shear strength of reinforced concrete beams (Trianafillou 1998).

\footnotetext{
${ }^{1)}$ Faculty of Engineering, Aksaray University, Ankara, Turkey.

*Corresponding Author;

E-mail: kaya261174@hotmail.com

${ }^{2)}$ Republic of Turkey Ministry of Health, Ankara, Turkey. Copyright $($ The Author(s) 2015. This article is published with open access at Springerlink.com
}

In this study, the effect of the number of anchorages that prevent separation of GFRP plates from the beam surface on the shear strength of beams was investigated. Five reinforced concrete beams with $\mathrm{T}$ cross-section with a length of $4000 \mathrm{~mm}$ were designed. One flexural reference specimen designed according to the disaster regulation (Regulation on Buildings Constructed in Disaster Areas 2007), 1 shear deficient reference specimen with insufficient shear reinforcement, and 3 strengthened specimens with GFRP were designed. GFRP plate span and width used in all strengthened specimens were the same. The number of anchorages used on these specimens was determined as 2, 3 and 4.

All beams were tested under monotonic loads. At the end of the test load capacity, energy dissipation, stiffness, ductility and collapsing mechanism of strengthened concrete beams with the different number of anchorages were compared to flexural reference specimen.

Trianafillou (1998) tested beams with a length of $1000 \mathrm{~mm}$, width of $70 \mathrm{~mm}$ and height of $110 \mathrm{~mm}$ and the shear reinforcement of which is not used by adhering their surfaces GFRP plate with different angle in the study performed. Khalifa and Nanni (2002) increased the shear strength of beams using GFRP in the different angle in the test specimens with $\mathrm{T}$ cross-section in the study they performed. Kachlakev and McCurry (2000) tested 4 beams with insufficient shear strength in the study they performed. One of the beams is a control specimen and another 3 of them are strengthened with GFRP and CFRP (Kachlakev and 
McCurry 2000). Raghu et al. (2000) aimed at increasing the shear strength of reinforced concrete beams with $\mathrm{T}$ crosssection using carbon FRPs in the study they performed. For this purpose, they applied GFRP plates on all beam surfaces with and without anchorage (Raghu et al. 2000). Li et al. (2001) tested the beams with insufficient shear reinforcement in the study they performed. The effect of the amount of GFRP used to strengthened beams on beam shear strength was researched ( $\mathrm{Li}$ et al. 2001). Ali et al. (2001) studied on separation mechanisms in the reinforcement of the beams in terms of bending and shear in the study they performed. In the study, the steel plates used for reinforcement and FRP plates were compared (Ali et al. 2001). Khalifa and Nanni (2000) increased the shear strength of beams with a rectangular cross-section using GFRP plate in the study they performed. Diagana et al. (2003) aimed at reinforcing rectangular beams with insufficient shear reinforcement against shear in the study they performed. GFRP plate was adhered on the surface of tested beams in 4 different forms. GFRP plates were adhered as perpendicular and $45^{\circ}$ to the horizontal (Diagana et al. 2003). Wegian and Abdalla (2006) strengthened beams against shear in the study they performed. GFRP, CFRP, and FRP were used on the specimens tested in the study (Wegian and Abdalla 2006). Riyadh and Riadh (2006) aimed at reinforcing the reinforced concrete beams against shear and bending with GFRP plates in the study they performed. Anil (2006) studied on strengthening of reinforced concrete beams against shear using GFRP plates. GFRP plate width and method of application of plates were determined as experiment parameters (Anil 2006). Bencardino et al. (2007) strengthened beams without shear reinforcement against shear using GFRP in the study they performed. Kang et al. (2014) used carbon fibers (CF) and glass fibers (GF) combined to strengthen concrete flexural members. In their study, data of tensile tests of 94 hybrid carbon-glass FRP sheets and 47 carbon and GF rovings or sheets were thoroughly investigated in terms of tensile behavior (Kang et al. 2014). Kang and Ary (2012) used fiber-reinforced polymers (FRP) to enhance the behavior of structural components in either shear or flexure. The research focused on the shear-strengthening of reinforced and pre-stressed concrete (PC) beams using FRP (Kang and Ary 2012). Ary and Kang (2012) experimentally evaluated the impact of carbon fiber-reinforced polymers (CFRP) amount and strip spacing on the shear behavior of PC beams and evaluated the applicability of existing analytical models of FRP shear capacity of PC beams shear-strengthened with CFRP. Kang et al. (2012) reviewed the debonding failure of FRP laminates externally attached to concrete. They also discussed the influences on bond strength and failure modes as well as the existing experimental research and developed equations (Kang et al. 2012).

A review of the literature shows that there is very limited research being carried out on the effect of the number of anchorage specimens (bolt) providing anchorage of plates used for strengthening of reinforced concrete beams against shear fracture. In this study, the effect of the number of anchorages that provide connection of GFRP on the beam surface was investigated.

\section{Experimental Study}

\subsection{General}

The most important factor that determines the collapse mechanism of reinforced concrete beams is the ratio of shear span $(a)$ to useful beam height $(d)$. Flexural failures rather than shear failures will govern the capacity of moderately long beams $a / d$ approximately equal to 5 .

Upon the increase of load on the beam firstly bending cracks arise, and upon the increase off -tensile strengths bending cracks arise. As a result of the combination of one or several bending cracks with sloping cracks the brittle cracks occur. When brittle crack occurred test specimen breaks without significant deformation (strain), and absorb relatively little energy prior to fracture.

It was aimed to see higher load capacity, stiffness, energy dissipation, and ductile behavior from strengthened DE3, DE4, and DE5 specimen than DE1 good reference. This beam shear span determined as $1550 \mathrm{~mm}$, useful height is determined as $330 \mathrm{~mm}$ and (a/d) determined as $(4,7)$. This dimension approximately equal to 5 (Kankal 2011).

\subsection{Detailing Test Specimens}

The test specimens were detailed in $1 / 2$ scale. Five beams were tested in the experimental program. The test specimens were designed as a $\mathrm{T}$ cross-section beam with a length of $4000 \mathrm{~mm}$. In the beam cross-section web width was designed as $120 \mathrm{~mm}$, beam height was designed as $360 \mathrm{~mm}$, topping concrete width was designed as $320 \mathrm{~mm}$ and topping concrete depth was designed as $75 \mathrm{~mm}$. 3Ø16, and $2 \varnothing 14$ longitudinal reinforcement was used in all specimens as tensile reinforcement. The percentage of tensile reinforcement in the beams is $\rho=0.0230$. Since this ratio is smaller than the balanced reinforcement ratio $\rho_{b}=0.0305$ specified in TS 500 (2000). $2 \varnothing 8$ longitudinal reinforcement was used as compressive reinforcement. Transverse reinforcements (stirrup) produced with Ø6 straight reinforcements were used in the beams. Stirrups were placed with a span of $75 \mathrm{~mm}$ in reference test specimens with sufficient shear reinforcement, shear transverse reinforcements were placed with a span of $300 \mathrm{~mm}$ in reference test specimens with insufficient shear reinforcement. The stirrup ratio in beams with insufficient shear reinforcement is $\rho_{w}=0.00157$. With this stirrup ratio, it was aimed to keep shear strength at the low level. The geometric form and reinforcement plan test specimens are given in Fig. 1.

Total 5 beams were produced for the experimental study, namely 1 flexural reference specimen with sufficient shear reinforcement, 1 shear deficient reference specimen with insufficient shear reinforcement, and 3 strengthened specimens with GFRP plates. In the other 3 test specimens, GFRP plates were adhered to beam side surfaces. The epoxy based adherent is used in adhering GFRP plates. Plate thickness was designed as $5 \mathrm{~mm}$, plate width was designed as $\left(w_{f}\right)$ $90 \mathrm{~mm}$ and the span between the axes of plates $\left(s_{f}\right)$ was designed as $100 \mathrm{~mm}$. In all strengthened specimens, the anchorage was used in order to prevent separation of GFRP 

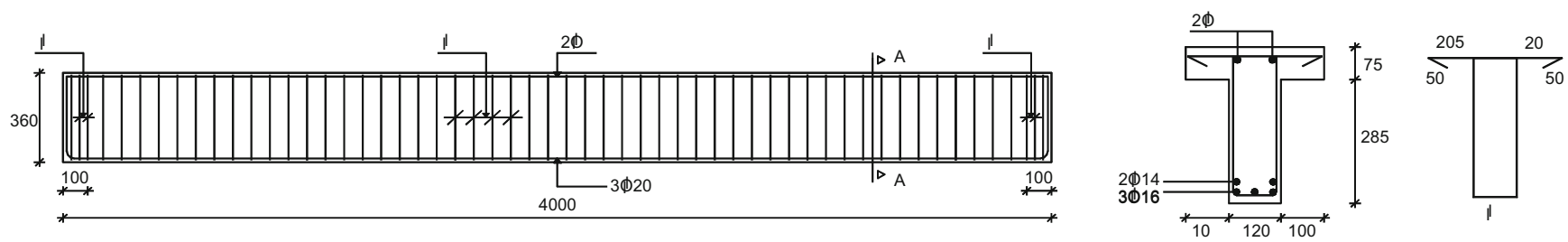

(a) DE1 Specimen

A-A
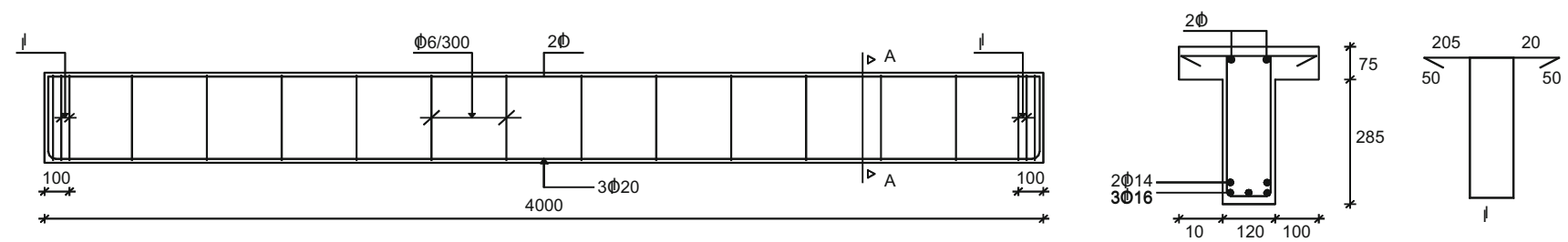

(b) DE2 Specimen

A-A

Fig. 1 DE1 and DE2 reference test specimens.

plates from the beam surface. The number of anchorages is different in each specimen. In the specimen with two anchorages, the span between anchorage axes was prepared as $180 \mathrm{~mm}$, the specimen with three anchorages anchorage the span between anchorage axes was prepared as $90 \mathrm{~mm}$ and the specimen with four anchorages the span between anchorage axes was prepared as $60 \mathrm{~mm}$. Reinforcement status of test specimens was given in Table 1. The plates were adhered to the beams to the same regions along the shear span. GFRP plate status of test specimens was given in Table 2 .

In the Regulation of the Buildings to be Constructed in Disaster Regions (Trianafillou 1998), there is the condition that if FRP is used in the form of plates the span between the axes of plates $\left(s_{f}\right)$ will be smaller than the sum of plate width $\left(w_{f}\right)$ and one-fourth of the useful beam height $(d)\left(w_{f}+d / 4\right)$ (Trianafillou 1998). The span between plate axes to be used according to this condition should be maximum $172.5 \mathrm{~mm}$ $(90+330 / 4=172.5)$. Since the span between the axes of GFRP plates is applied as $100 \mathrm{~mm}$ in this study, a design was made in conformity with the values in regulations. A strengthening technique performed in the beams by adhering carbon fiber and glass FRPs by Anil (2006).

In this study, the anchorage was used in order to prevent separation of GFRP plates from the beam surface. Keeping this study effect of the number of anchorages on the load capacity, stiffness, energy dissipation, ductility, and collapse mode of strengthened beams was investigated. In the experimental studies performed, the issue that the ratio between the effective anchorage depth to anchorage diameter was considered as 5 . The anchorage diameter was applied at approximately $8 \mathrm{~mm}$ in the experimental study mild steel bolt was used as an anchorage. Consequently, the ratio between the anchorage depth to anchorage diameter was provided. Anchorage status of test specimens was given in Table 3. GFRP plate placement used on the specimens and anchorage details was given in Fig. 2.

\subsection{Properties and Strengths of Materials}

For correct examination of the results of the experimental study, the test specimens were produced from materials with similar characteristics. For this purpose, the mechanical properties of the materials used in the experimental study became the same.

\subsubsection{Concrete and Reinforcement}

A compressive concrete strength of $16 \mathrm{MPa}$ was used in this experimental study based on the average strength of an existing building collapsed during the 1999 Izmit earthquake event. Concrete samples were tested in order to determine the compressive strength for 28 days after being kept waiting in cure pool in the laboratory environment. The strength of the concrete samples is presented in Table 4. Since the difference between the compressive strength of the concrete samples did not exceed $2 \%$, normalization was not performed on the concrete strength. The properties of the reinforcements used in the test specimens were given in Table 5 .

Table 1 Reinforcement status of test specimens.

\begin{tabular}{c|c|c|c|c}
\hline Test specimens & $(a / d)$ & Longitudinal reinforcement & Shear reinforcement & Shear reinforcement ratio \\
\hline \hline DE1 (reference) & 4,7 & $3 \varnothing 16+2 \varnothing 14$ & $\varnothing 6 / 75$ & 0.00628 \\
\hline DE2 (reference) & 4,7 & $3 \varnothing 16+2 \varnothing 14$ & $\varnothing 6 / 300$ & 0.00157 \\
\hline DE3 (strengthening) & 4,7 & $3 \varnothing 16+2 \varnothing 14$ & $\varnothing 6 / 300$ & 0.00157 \\
\hline DE4 (strengthening) & 4,7 & $3 \varnothing 16+2 \varnothing 14$ & $\varnothing 6 / 300$ & 0.00157 \\
\hline DE5 (strengthening) & 4,7 & $3 \varnothing 16+2 \varnothing 14$ & $\varnothing 6 / 300$ & 0.00157 \\
\hline
\end{tabular}


Table 2 GFRP plate status of test specimens.

\begin{tabular}{c|c|c|c|c}
\hline Test specimen & GFRP length (mm) & GFRP width (mm) & GFRP thickness (mm) & GFRP space (mm) \\
\hline \hline DE1 (reference) & - & - & - & - \\
\hline DE2 (reference) & - & - & - & - \\
\hline DE3 (strengthening) & 280 & 90 & 5 & 100 \\
\hline DE4 (strengthening) & 280 & 90 & 5 & 100 \\
\hline DE5 (strengthening) & 280 & 90 & 5 & 100 \\
\hline
\end{tabular}

Table 3 Anchor conditions of test specimens.

\begin{tabular}{c|c|c|c}
\hline Specimen number & Anchor diameter $(\mathrm{mm})$ & Anchor number & Anchor distance (mm) \\
\hline \hline DE1 (reference) & - & - & - \\
\hline DE2 (reference) & - & 2 & 180 \\
\hline DE3 (strengthening) & 8 & 3 & 90 \\
\hline DE4 (strengthening) & 8 & 4 & 60 \\
\hline DE5 (strengthening) & 8 & - & \\
\hline
\end{tabular}
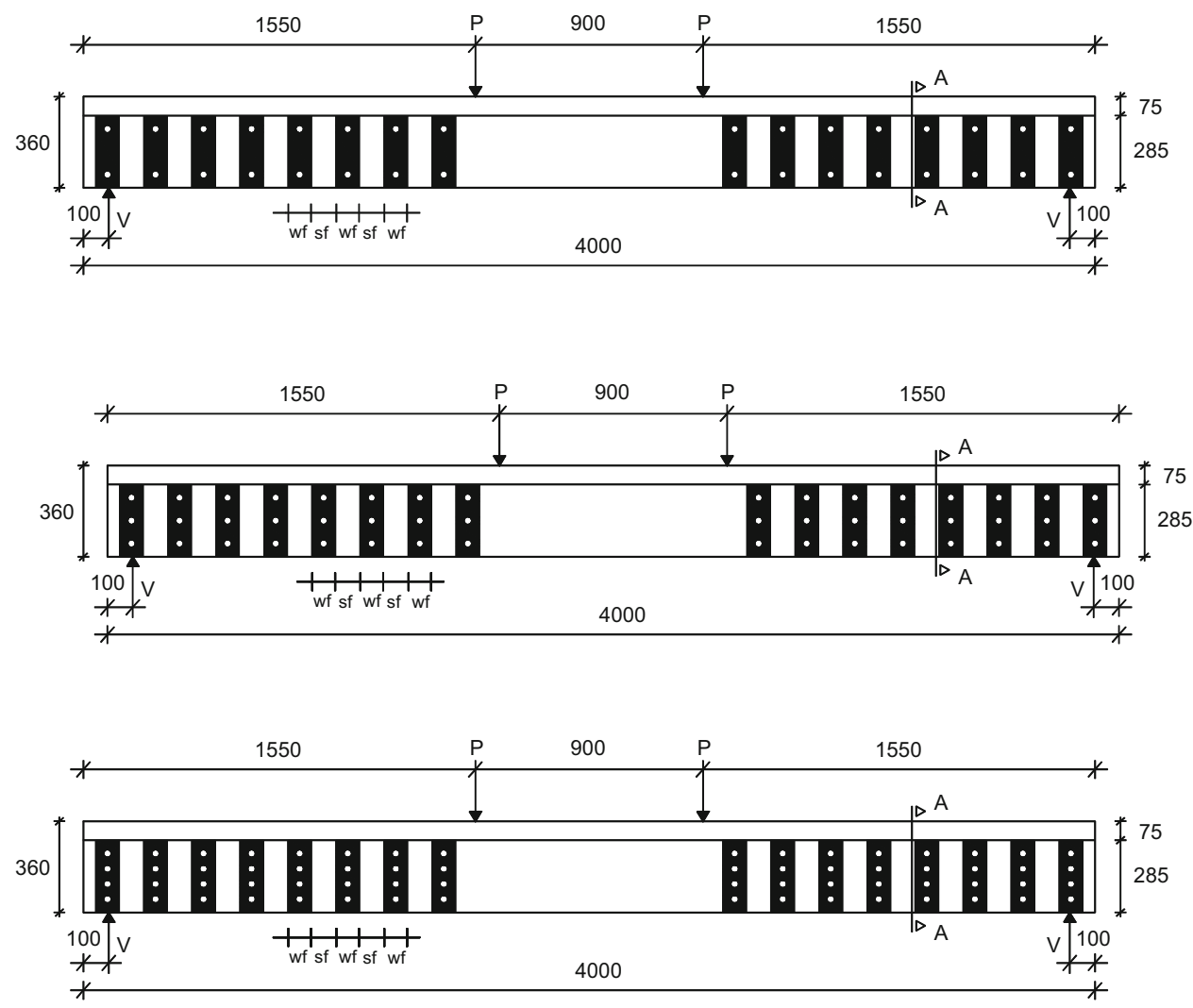

$w_{f}: 90 \mathrm{~mm} \quad s_{f}: 100 \mathrm{~mm}$
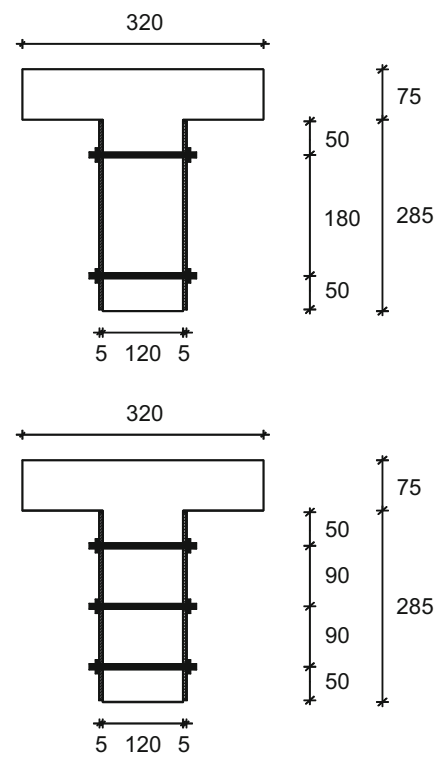

320

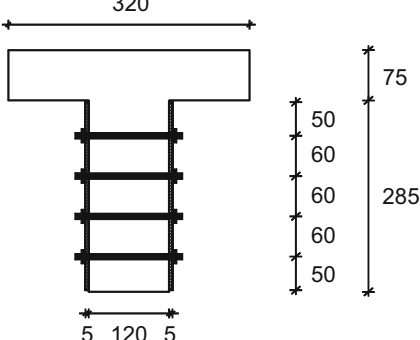

Fig. 2 DE3, DE4 and DE5 reinforced test specimens.

\subsubsection{GFRP}

Glass fiber is composed of silica sand $\left(\mathrm{SiO}_{2}\right)$ which makes up the oxides and bases of sodium, calcium, aluminum, boron and iron specimens. Glass is the cheapest and most easily obtained strengthening material among the materials used in the production of fiber polymer. Glass fiber reinforcement polymer (GFRP) used in test specimens was produced by Dogus Plastic Industry (www.dogusplastiksanayi. com/index.php?pg=epoxy. 23 Haziran 2011). The properties of GFRP used in the test specimens were given in Table 6. 
Table 4 Concrete specimens average compressive strengths.

\begin{tabular}{c|c}
\hline Specimen number & Concrete compressive strength (MPa) \\
\hline 1 & 15.8 \\
\hline 2 & 16.0 \\
\hline 3 & 16.2 \\
\hline 4 & 15.9 \\
\hline 5 & 16.4 \\
\hline 6 & 16.1 \\
\hline
\end{tabular}

Table 5 Yielding and tensile strengths of the mild steel used at the experiments.

\begin{tabular}{c|c|c|c}
\hline Reinforcement diameter & Steel class & Yielding stress (MPa) & Fracture stress (MPa) \\
\hline \hline 66 & S220 & 390 & 630 \\
\hline$\varnothing 8$ & S420 & 440 & 670 \\
\hline$\varnothing 14$ & S420 & 450 & 680 \\
\hline$\varnothing 16$ & S420 & 470 & 695 \\
\hline
\end{tabular}

Table 6 Properties of GFRP.

\begin{tabular}{c|c}
\hline Unit weight $\left(\mathrm{g} / \mathrm{cm}^{3}\right)$ & $1.5-2.1$ \\
\hline Tensile strength $(\mathrm{MPa})$ & $200-340$ \\
\hline Impact strength $(\mathrm{MPa})$ & 33 \\
\hline
\end{tabular}

\subsubsection{Epoxy}

Sikadur 31 (www.sika.com.tr/index.php?s=2\&s2=products $\& s 3=4.23$ Haziran 2011) was used to adhere GFRP plates on beam surfaces. Sikadur 31 is structural adhering and repair mortar with moisture tolerance, 2 components, containing epoxy resins and special filling. The mechanical/physical properties of Sikadur 31, epoxy adherent were given in Table 7.

\subsection{Production of Test Specimens} 2.4.1 Preparing Reinforcements

The production was started with the production of reinforcement in the beams. $3 \varnothing 16$ and $2 \varnothing 14$ ribbed reinforcement was used in the tensile surfaces of all beams. The tensile reinforcement ratio in beams is $\rho=0.0230$. By designing the tensile reinforcement ratio in the beam as smaller than $\rho_{b}=0.0305$, the balanced reinforcement ratio.

Table 7 Sikadur 31 epoxy mechanical and physical properties.

\begin{tabular}{|c|c|c|c|}
\hline & \multirow[t]{2}{*}{ Cure duration } & \multicolumn{2}{|c|}{ Cure temperature } \\
\hline & & $+20{ }^{\circ} \mathrm{C}$ & $+10{ }^{\circ} \mathrm{C}$ \\
\hline \multirow[t]{4}{*}{ Compressive strength } & 1 days & $40-45 \mathrm{~N} / \mathrm{mm}^{2}$ & $35-40 \mathrm{~N} / \mathrm{mm}^{2}$ \\
\hline & 10 days & $60-70 \mathrm{~N} / \mathrm{mm}^{2}$ & $50-60 \mathrm{~N} / \mathrm{mm}^{2}$ \\
\hline & \multirow{2}{*}{\multicolumn{2}{|c|}{ Cure duration }} & Cure temperature \\
\hline & & & $+10^{\circ} \mathrm{C}$ ile $+20^{\circ} \mathrm{C}$ \\
\hline Flexural strength & \multicolumn{2}{|c|}{10 days } & $30-40 \mathrm{~N} / \mathrm{mm}^{2}$ \\
\hline Tensile strength & \multicolumn{2}{|c|}{10 days } & $15-20 \mathrm{~N} / \mathrm{mm}^{2}$ \\
\hline \multirow[t]{2}{*}{ Adhesion strength } & \multicolumn{2}{|c|}{10 days (concrete) } & $3.0-3.5 \mathrm{~N} / \mathrm{mm}^{2}$ \\
\hline & \multicolumn{2}{|c|}{10 days (steel) } & $15 \mathrm{~N} / \mathrm{mm}^{2}$ \\
\hline Modules of elasticity & \multicolumn{3}{|c|}{$4300 \mathrm{~N} / \mathrm{mm}^{2}$} \\
\hline Density & \multicolumn{3}{|c|}{$1.65 \mathrm{~kg} / 1$} \\
\hline
\end{tabular}




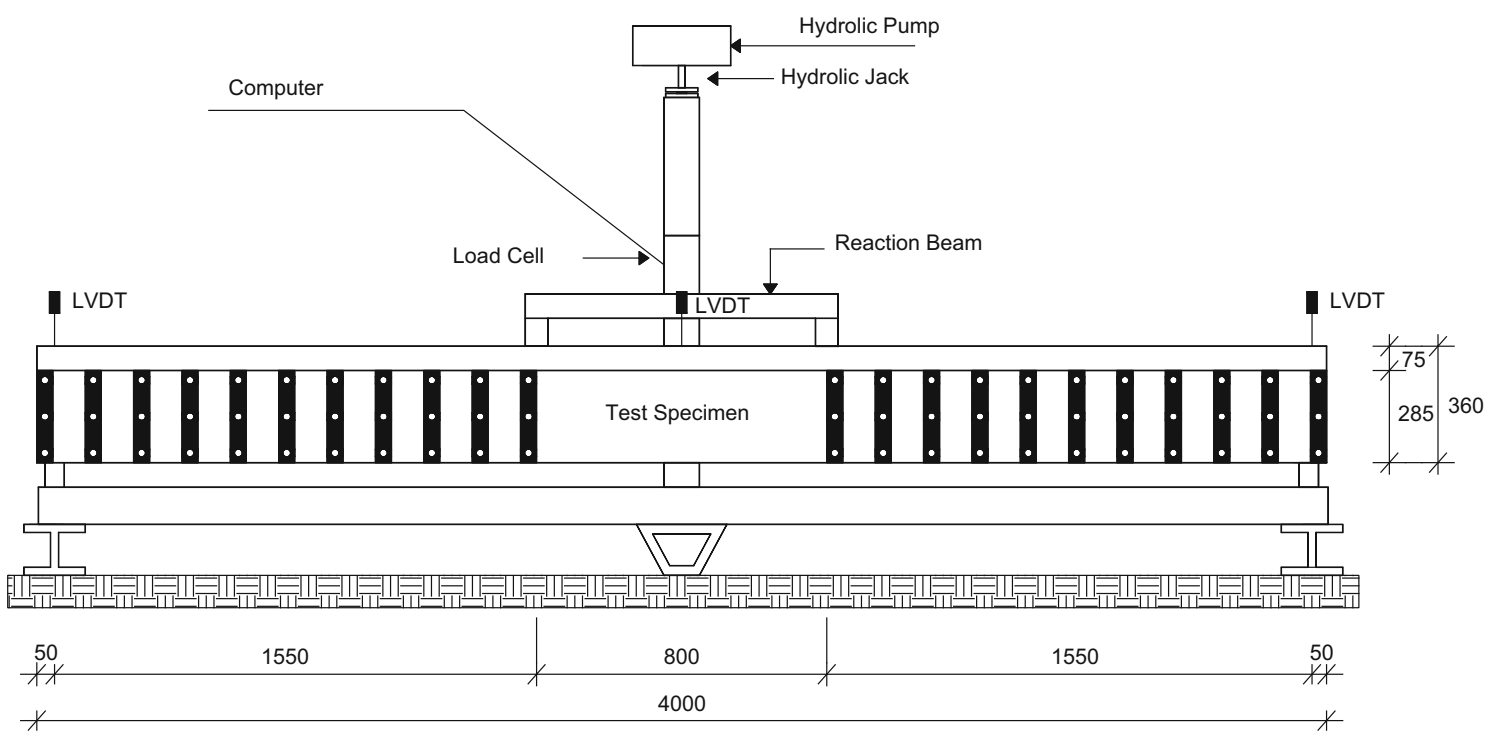

Fig. 3 Test setup and measurement system.

Shear reinforcements in DE1 were placed with spans of $75 \mathrm{~mm}$. Straight closed stirrups with a diameter of $6 \mathrm{~mm}$ were used as shear reinforcement.

Stirrups with a diameter of $6 \mathrm{~mm}$ were placed with spans of $300 \mathrm{~mm}$ as shear reinforcement in all test specimens except for DE1. This stirrup ratio is $\rho_{\mathrm{w}}=0.00157$ and it is approximate $1 / 4$ of the stirrup ratio to be found. Using insufficient shear reinforcement in the specimens, it was aimed to create the shear crack. Three transverse reinforcements were placed in beam ends with spans of $30 \mathrm{~mm}$ in order to prevent the local break in beams.

\subsubsection{Concrete Casting}

Concrete casting was applied to test specimens which were made ready for concrete casting. C16 ready made concrete was used in the casting. The concrete vibrator was used during concrete casting in order to place the concrete homogeneously in the mold. Concrete test specimens which were removed from the mold and which took hardening of minimum 28 days were drilled from the marked points in order to fit anchorage bolts. The diameter of anchorage holes is $10 \mathrm{~mm}$.

\subsubsection{Preparing Anchorages}

Mild steel bolts with diameters of $8 \mathrm{~mm}$ were used for reinforcement of test specimens. Anchorages were not used in reference test specimens numbered 1 and 2 . Two anchorages were used per GFRP plate in the test specimens numbered 3. Three anchorages were used per GFRP plate in the test specimens numbered 4. Four anchorages were used per GFRP plate in the test specimens numbered 5 .

\subsubsection{Preparing GFRP Plates}

The regions where GFRP plates will be adhered are marked inside surfaces of beams. Those regions marked were cleaned in order to create solid and clean adherence surface. Cleaning the concrete grouting from the surface area where GFRP plates will be adhered is very significant for providing adherence between the adhesive and the concrete. The points where anchorage bolts will be placed on GFRP plates were marked and the marked points were drilled in order to pass anchorage bolts in it. Drilled GFRP plates were made ready to be adhered to beam side surface. The surfaces where GFRP plates will be adhered were applied Sikadur 31 epoxy adherent with a thickness of $1 \mathrm{~mm}$. After the GFRP plates were adhered to beam side surface and those plates were fixed with anchorage bolts, the strengthening process was completed and the beams to be tested were made ready to be placed in the loading system.

\subsection{Loading and Measurement System}

The loading program was applied to the specimens as load-controlled until the specimens collapsed. The loading program was manually applied to the specimens at the same loading velocity. The loads and displacements observed in the specimens during the loading steps were monitored via the computer display.

The load was applied to test specimens with $50 \mathrm{kN}$ capacity mechanic pump connected to a hydraulic jack and the applied load was measured with $40 \mathrm{kN}$ capacity load cell. The reaction was placed on the test specimens as simple support. The single load with $P$ size transmitted to the reaction beam from the hydraulic jack was transmitted to the test specimens in the form of two equal single loads with $P / 2$ sizes. The loading was started from zero and continued till collapse. Test setup and measurement system in the test specimens were given in Fig. 3.

Electronic measurement devices (LVDT) were placed on the midpoint of the beam on the sports in order to determine midpoint displacement of test specimens. To determine the midpoint displacement $200 \mathrm{~mm}$ capacity LVDT was used. To determine right, and left supports displacements $100 \mathrm{~mm}$ capacity LVDTS were used. The load, and displacement values were used to draw load-displacement curves of test specimens. 
The net displacement at the end of the beams measured from the LVDT (D0) were equal to the difference of the average vertical displacements of the D1 and D2 LVDTS.

\section{Experimental Test Results}

The DE1 test specimen was a reference specimen with sufficient shear reinforcement prepared to be compared to strengthened test specimen.

The first bending crack in this specimen was occurred in the fixed moment region at the load of $45.4 \mathrm{kN}$. The midpoint displacement measured when the first crack occurred is $3.80 \mathrm{~mm}$. Bending cracks at a load of $170.0 \mathrm{kN}$ reached a width up to $1 \mathrm{~mm}$. At the load of $180.24 \mathrm{kN}$ tensile reinforcement started to yield. At that load, midpoint displacement was measured as $25.42 \mathrm{~mm}$. While there was no definite increase in the load capacity of the specimen after that load, the midpoint displacement continued to increase. The highest load value in the test specimen was measured as $187.38 \mathrm{kN}$. The midpoint displacement at that value became $51.95 \mathrm{~mm}$. At the load value of $185.96 \mathrm{kN}$, the test specimen collapsed as a result of the crash of concrete in the concrete compressive region. The midpoint displacement measured in the test specimen during the collapse is $56.08 \mathrm{~mm}$. The collapse of this test specimen happened in the form of bending fracture. The view of the test specimen after a collapse is shown in Fig. 4.

The DE2 test specimen was a reference specimen with insufficient shear reinforcement prepared to be compared to strengthened test specimen. The first crack in DE2 was occurred in the fixed moment region in the form of bending crack at the load of $39.2 \mathrm{kN}$ and at $3.98 \mathrm{~mm}$ midpoint displacement value. In parallel with the increase of loading, shear cracks arose. Two shear cracks became at the load of $130.0 \mathrm{kN}$ in the right shear span. The test specimen collapsed as a result of the main shear crack at a load of 138.76 $\mathrm{kN}$ in the right shear span and reaching the topping concrete. When the specimen collapsed, midpoint displacement of $22.07 \mathrm{~mm}$ was measured in the test specimen. The collapse of this test specimen happened in the form of shear fracture. The view of DE2 after the collapse is shown in Fig. 5.

The DE3 test specimen was a strengthened with GFRP plates of which 2 anchorages were used. The first bending

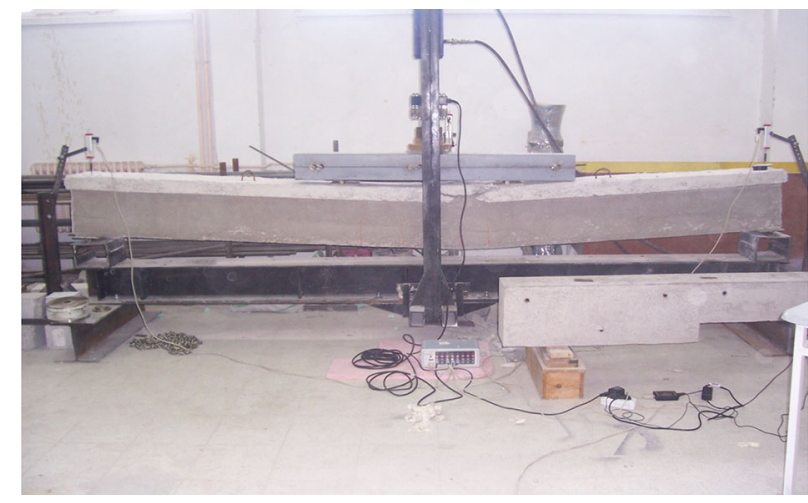

Fig. 4 View of the DE1 specimen after test finished. crack in DE3 occurred at the of $41.0 \mathrm{kN}$ load and midpoint displacement of $3.64 \mathrm{~mm}$. The first shear crack occurred at a load of $130.0 \mathrm{kN}$ in the right shear span. The crack occurred in the plate numbered 5 and passed under the plate, and reached a thickness of $1 \mathrm{~mm}$. Two main shear cracks became at the load of $168.0 \mathrm{kN}$ in left shear span the plates numbered 3 and 6 passed and passed under the plates plates numbered 4 and 5 . As a result of the arrival of this main crack to the topping concrete, the Specimen collapsed at a load of $169.08 \mathrm{kN}$. The midpoint displacement of the specimen measured at the load of collapse is $28.23 \mathrm{~mm}$. The view of DE3 after a collapse is shown in Fig. 6. The collapse of this specimen happened in the form of shear failure.

The DE4 test specimen was a strengthened with GFRP plates of which 3 anchorages were used. The first bending crack in this specimen occurred at $43.8 \mathrm{kN}$ load. At that load in the same specimen, midpoint displacement was measured as $3.79 \mathrm{~mm}$. When it reached to a load level of $100.0 \mathrm{kN}$, the first shear crack occurred in the right shear span. The first shear crack that occurred in the right shear span passed under the plate numbered 12 reached to the plate numbered 13. The specimen collapsed at a load of $174.94 \mathrm{kN}$ with sudden and brittle as a result of shear crack that occurred under the plates numbered 11 and 12 reaching to the topping concrete. The midpoint displacement of the specimen measured at the moment of collapse is $28.45 \mathrm{~mm}$. The collapse of this specimen happened in the form of shear failure. The view of after a collapse is shown in Fig. 7.

The DE5 test specimen was a strengthened with GFRP plates of which 4 anchorages were used. The first bending crack in DE5 occurred in the maximum moment region at a load of $43.2 \mathrm{kN}$ and at midpoint displacement of $3.65 \mathrm{~mm}$. Upon the increase in load cracks in the specimen continued to increase. Tensile reinforcement began to yield at the load of $178.28 \mathrm{kN}$. The midpoint displacement at the moment of yield was measured as $25.44 \mathrm{~mm}$. While the load applied stayed approximately the same upon the increase of the loading, the midpoint displacement continued to increase. Beam maximum load capacity was reached at a load of $186.04 \mathrm{kN}$ and midpoint displacement value of $44.38 \mathrm{~mm}$. Specimen collapsed upon the crush of topping concrete in

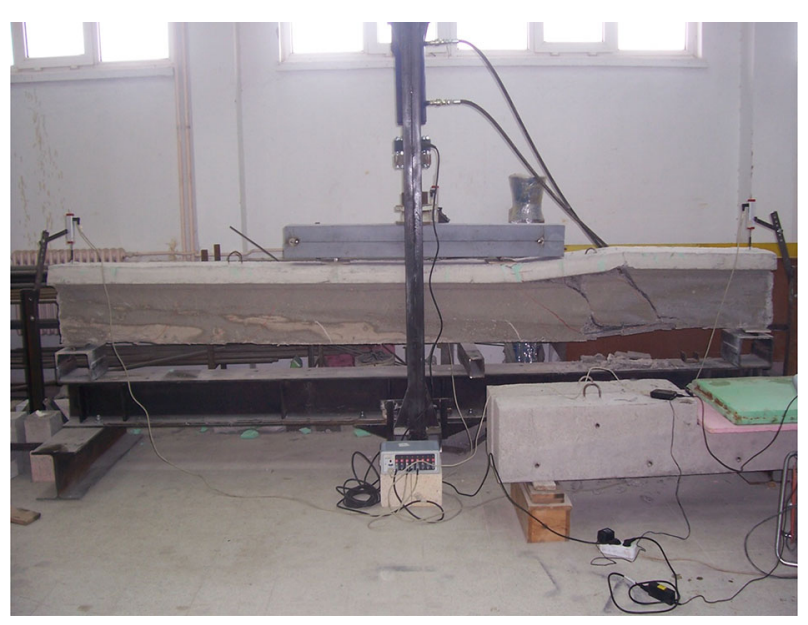

Fig. 5 View of the DE2 specimen after test finished. 


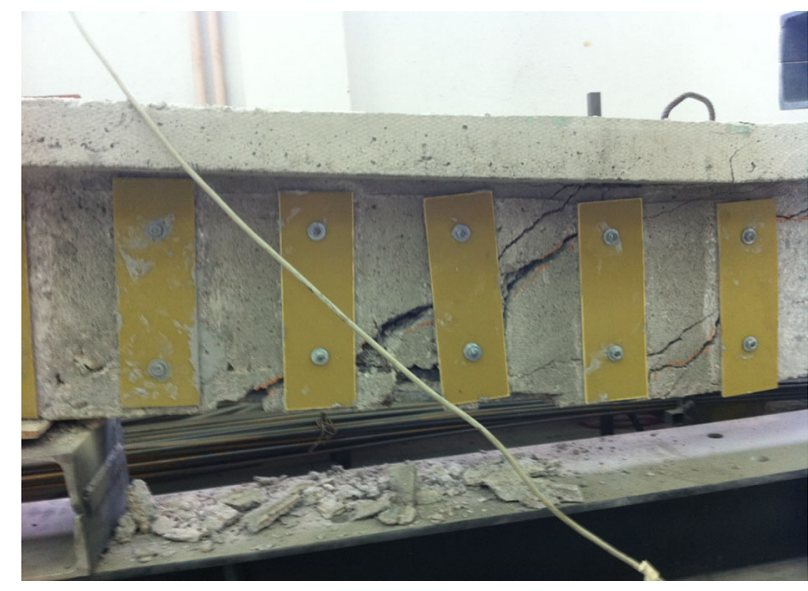

Fig. 6 View of the DE3 specimen after test finished.

the compressive region at a load of $185.30 \mathrm{kN}$. The midpoint displacement of $44.98 \mathrm{~mm}$ was measured at the load of collapse. The test specimen's collapse mechanism is in the mode of bending fracture. Tensile reinforcement in the specimen yielded and a ductile behavior was observed. The view of DE5 after a collapse is shown in Fig. 8.

\section{Comparison of Experiment Results}

The results obtained from the experiments were compared. In the comparison, response envelopes of test specimens were used (Fig. 9). Furthermore, test specimens' yield load, collapse load, yield and collapse displacements, stiffness, and energy dissipation capacities were compared (Table 8).

\subsection{Behavior of Test Specimens}

The load displacement curves of the reference test specimen DE1 with sufficient shear reinforcement, DE2 the reference test specimens with insufficient shear reinforcement, and strengthened with different numbers of anchorages DE3, DE4 and DE5 test specimens were compared in Fig. 9. The reference test specimen with sufficient shear reinforcement (DE1) is the flexural reference specimen to which strengthening was not applied. This test specimen carried $34 \%$ more load compared to the insufficient shear reinforcement (DE2). DE1 shear reinforcement sufficient specimen carried $10 \%$

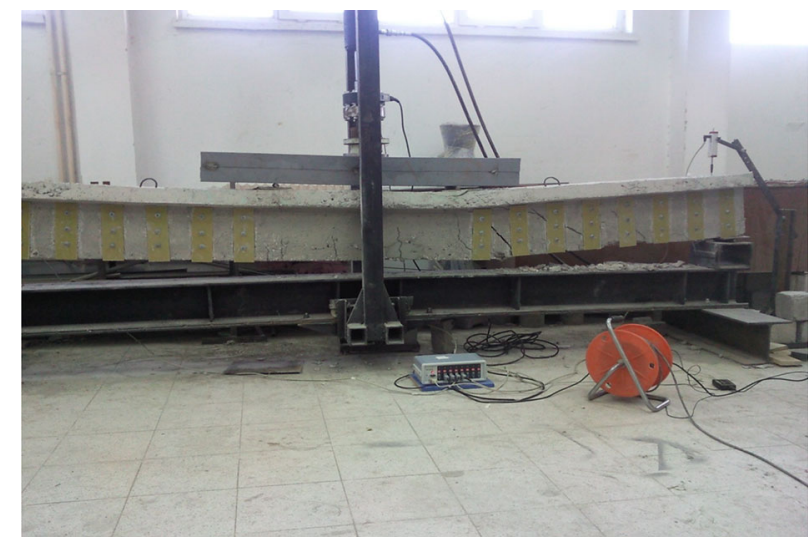

Fig. 7 View of the DE4 specimen after test finished. more load compared to the insufficient shear reinforcement DE3 specimen. DE1 test specimen carried $8 \%$ more load compared to the insufficient shear reinforcement DE4 specimen. DE1 shear reinforcement sufficient specimen specimen carried approximately equal load with strengthened specimen (DE5) for which four anchorages were used.

The shear reinforcement sufficient reference specimen DE1 lost its load capacity at $185.96 \mathrm{kN}$. This specimen made $56.08 \mathrm{~mm}$ displacement at maximum load, and collapsed as a result of the flexural collapse.

The shear reinforcement insufficient reference specimen (DE2) lost its load capacity at $138.76 \mathrm{kN}$. This specimen made $22.07 \mathrm{~mm}$ displacement at maximum load, and collapsed as a result of the shear fracture.

The DE3 specimen for which 2 anchorages were applied to GFRP plates carried a load of $169.08 \mathrm{kN}$, and it collapsed at that load as a result of the shear fracture. The midpoint displacement of this specimen measured at the load of collapse reached to $28.23 \mathrm{~mm}$. This specimen collapsed suddenly and in a brittle manner as a result of the shear crack.

The DE4 specimen for which 3 anchorages were applied to GFRP plates reached maximum load capacity at a load of $174.94 \mathrm{kN}$ and the midpoint displacement was measured as $28.45 \mathrm{~mm}$ at that load. This specimen collapsed suddenly and in a brittle manner as a result of the shear crack.

The DE5 specimen for which 4 anchorages were applied to GFRP plates reached maximum load capacity at a load of $185.30 \mathrm{kN}$, and the midpoint displacement was measured as $44.98 \mathrm{~mm}$ at that load. This specimen carried approximately equal load with DE1 reference test specimen which is the flexural reference. This specimen reached higher load capacity, and midpoint displacement compared to other shear reinforcement insufficient DE2, strengthened DE3, and DE4 test specimens.

While the number of anchorages applied to GFRP plates increased, load capacity of specimens increased and DE5 specimen which was applied the highest number of anchorages (4 anchorages) carried approximately equal load with DE1 specimen This test specimen (DE5) exhibited ductile behavior and collapsed as a result of the yield of bending reinforcement (Table 9).

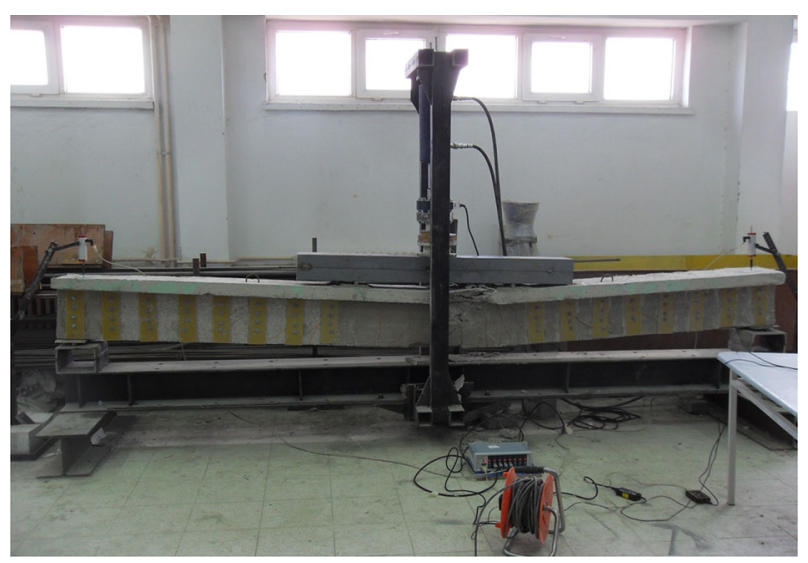

Fig. 8 View of the DE5 specimen after test finished. 


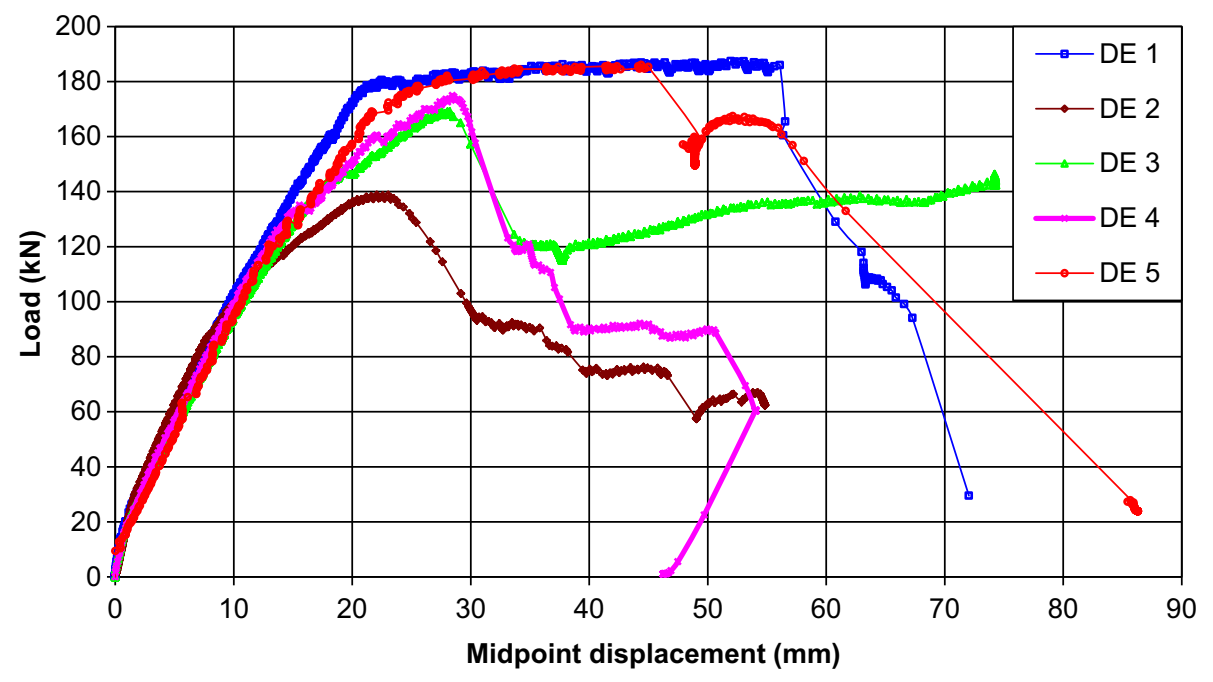

Fig. 9 Superpose load-displacement curves of the test specimens.

Table 8 Test results.

\begin{tabular}{c|c|c|c|c|c}
\hline Specimen number & Yielding load $(\mathrm{kN})$ & $\begin{array}{c}\text { Yielding displacement } \\
(\mathrm{mm})\end{array}$ & Fracture load $(\mathrm{kN})$ & $\begin{array}{c}\text { Fracture displacement } \\
(\mathrm{mm})\end{array}$ & Fracture mechanism \\
\hline \hline DE1 & 180.24 & 25.42 & 185.96 & 56.08 & Flexure \\
\hline DE2 & - & - & 138.76 & 22.07 & Shear \\
\hline DE3 & - & - & 169.08 & 28.23 & Shear \\
\hline DE4 & - & - & 174.94 & 28.45 & Shear \\
\hline DE5 & 178.28 & 25.44 & 185.30 & 44.98 & Flexure \\
\hline
\end{tabular}

\subsection{Stiffness}

Stiffness of the test specimens were assessed as initial stiffness, at the yield load, and at the collapse loads. Initial stiffness were determined as the slope at the place in the load-displacement curve where the first crack was seen. Similarly, stiffness at yield load was determined as the ratio of the load at the yield to the displacement at the yield, and stiffness at collapse was determined as the ratio of the load at the collapse to the displacement at the collapse. Initial stiffness, stiffness at yield, and stiffness at collapse values were given in Table 10 .

The DE5 specimen exhibited approximately the same initial and yield stiffness with the reference shear reinforcement sufficient DE1 specimen. DE2, DE3, and DE4 strengthened specimens initial stiffness equal to DE1 DE \% specimens initial stiffness. Since tensile reinforcement did not yield in DE2, DE3, and DE4 specimens, the yield stiffness could not be calculated.

\section{Summary and Conclusions}

In this study, strengthening of RC beams against shear fracture by using epoxy adhered GFRP plates with different anchorage number was investigated. Roughening of the concrete surfaces, cleaning of these surfaces and complying completely with the epoxy application procedures was crucial for successful bonding. Also anchorage bolts strengths, process order was very important for this study. In these type applications, after the plates adhered on the beam faces, anchorages installed in the holes before epoxy hardened. Also, $1 \mathrm{~mm}$ thick steel material used between plate and beam faces to provide uniform epoxy thickness. Results obtained from the experimental research are as follows:

Load capacity of strengthened test specimens has increased compared to the load capacity of the shear deficient reference specimen DE2. DE3 carried $22 \%$ more load than DE2, DE4 carried $26 \%$ more load than DE2, and DE5 carried $34 \%$ more load than DE2. Increasing the number of anchorages used for strengthening, increased the load capacity of the specimen as well.

Upon the increase of the number of anchorages used in a strengthening collapsing manner of test specimens changed and load capacity thereof increased. The DE5 specimen for which the highest amount of anchorages were used was fractured by exhibiting ductile behavior as a result of the yield of bending reinforcement.

The dissipated energy amount by strengthened DE5 specimen was $4 \%$ lower than the dissipated energy amount by strengthened DE1. 
Table 9 Displacement-ductility ratio.

\begin{tabular}{c|c|c|c}
\hline Specimen number & Yielding displacement & Fracture displacement & Ductility ratio \\
\hline \hline DE1 & 25.42 & 56.08 & 221 \\
\hline DE2 & - & 22.07 & - \\
\hline DE3 & - & 28.23 & - \\
\hline DE4 & - & 28.45 & - \\
\hline DE5 & 25.44 & 44.98 & 177 \\
\hline
\end{tabular}

Table 10 Stiffness of test specimens.

\begin{tabular}{c|c|c|r}
\hline Test specimen & Initial stiffness & Yielding stiffness & Fracture stiffness \\
\hline \hline 1 & 11.9 & 71 & 3.31 \\
\hline 2 & 9.85 & - & 6.29 \\
\hline 4 & 11.26 & - & 5.99 \\
\hline 5 & 11.56 & - & 6.15 \\
\hline
\end{tabular}

The collapse of the DE5 test specimen happened in the form of bending fracture. While the number of anchorages used in GFRP plates increased in strengthening, ductility of specimens increases.

Upon using anchorage separation of GFRP plates from beam surface in strengthened test specimens, was prevented. No separation of GFRP plates from beam surface was observed in the test specimens.

No cracks were seen in GFRP plates, because these plates thickness and strength was enough to carry forces applied them.

\section{Open Access}

This article is distributed under the terms of the Creative Commons Attribution 4.0 International License (http://creativecommons.org/licenses/by/4.0/), which permits unrestricted use, distribution, and reproduction in any medium, provided you give appropriate credit to the original author(s) and the source, provide a link to the Creative Commons license, and indicate if changes were made.

\section{References}

Ali, M. S. M., Oehlers, D. J., \& Park, S. M. (2001). Comparision between FRP and steel plating of reinforced concrete beams. Composites Part A Applied Science and Manufacturing, 32(9), 1319-1328.

Anıl, O. (2006). Improving shear capacity of RC T-beams using GFRP composites subjected to cyclic load. Cement \& Concrete Composites, 28(7), 638-649.

Ary, M. I., \& Kang, T. H.-K. (2012). Shear-strengthening of reinforced \& prestressed concrete beams using FRP: Part
I-Review of Previous Research. International Journal of Concrete Structures and Materials, 6(1), 41-48.

Bencardino, F., Spadea, G., \& Swamy, R. N. (2007). The problem of shear in RC beams strengthened with GFRP laminates. Construction and Building Materials, 21(11), 1997-2006.

Diagana, A., Li, A., Gedalia, B., \& Delmas, Y. (2003). Shear strengthening with CFF strips. Engineering Structures, 25(4), 507-516.

Kachlakev, D., \& McCurry, D. D. (2000). The behavior of fullscale reinforced concrete beams retrofitted for shear and flexural with FRP laminates. Composites Part B: Engineering, 31(6-7), 445-452.

Kang, T. H.-K., \& Ary, M. I. (2012). Shear-strengthening of reinforced \& Prestressed concrete beams using FRP: Part II-Experimental Investigation. International Journal of Concrete Structures and Materials, 6(1), 49-57.

Kang, T. H.-K., Howell, J., Kim, S., \& Lee, D. J. (2012). A State-of-the-Art Review on Debonding Failures of FRP Laminates Externally Adhered to Concrete. International Journal of Concrete Structures and Materials, 6(2), 123-134.

Kang, T. H.-K., Kim, W., Ha, S.-S., \& Choi, D.-U. (2014). Hybrid Effects of Carbon-Glass FRP Sheets in Combination with or without Concrete Beams. International Journal of Concrete Structures and Materials, 8(1), 27-42.

Kankal, Z. Ç. (2011). Effect of Anchorage Number on Strengthening Reinforced Concrete Beams Against Shear With GFRP, Ms. Thesis. Aksaray, Turkey: Aksaray University.

Khalifa, A., \& Nanni, A. (2000). Improving shear capacity of existing RC T-section beams using GFRP composites. Cement \& Concrete Composites, 22(3), 165-174.

Khalifa, A., \& Nanni, A. (2002). Rehabilitation of rectangular simply supported RC beams with shear deficiencies using GFRP composites. Construction and Building Materials, 16(3), 135-146. 
Li, A., Diagana, C., \& Delmas, Y. (2001). GFRP contribution to shear capacity of strengthened RC beams. Engineering Structures, 23(10), 1212-1220.

Raghu, A., Bette Meyer, M. M., Myers, J. J., \& Nanni, A. (2000). An assessment of in situ FRP shear and flexural strengthening of reinforced concrete joists, ASCE Structures Congress, Philadelphia, PA, M. Elgaaly, Ed., May $8-10$, CD version, 8 .

Regulation on Buildings Constructed in Disaster Areas. (2007). The Ministry of Public Works and Settlement, Ankara, Turkey.

Riyadh, A., \& Riadh, A. (2006). Coupled flexural-shear retrofitting of RC beams using GFRP straps. Composite Structures, 75(1-4), 457-464.
Trianafillou, T. C. (1998). Shear strengthening of RC beams using epoxy bonded FRP composites. ACI Structural Journal, 95(2), 107-115.

Wegian, F. M., \& Abdalla, H. A. (2006). Shear capacity of concrete beams reinforced with fiber reinforced polymers. Composite Structures, 71(1), 130-138.

URL-1, www.dogusplastiksanayi.com/index.php?pg=epoxy. 23 Haziran 2011.

URL-2, www.sika.com.tr/index.php?s=2\&s2=products\&s $3=4$. 23 Haziran 2011. 